\title{
The Energy Concept and its Relation to Climate Literacy
}

\author{
Dirk Mittenzwei ${ }^{1 *}$, Till Bruckermann ${ }^{1}$, Jeffrey Nordine ${ }^{2}$, Ute Harms ${ }^{1}$ \\ ${ }^{1}$ Department of Biology Education, Leibniz Institute for Science and Mathematics Education (IPN), Olshausenstrasse 62, 24118 \\ Kiel, GERMANY \\ ${ }^{2}$ Department of Physics Education, Leibniz Institute for Science and Mathematics Education (IPN), Olshausenstrasse 62, 24118 \\ Kiel, GERMANY
}

Received 18 May 2018 - Revised 9 January 2019 - Accepted 30 January 2019

\begin{abstract}
Climate change is one of the most significant socio-scientific challenges of this century. To address this challenge, people need to be empowered to assess information about climate change and make informed decisions. Both aspects are covered by the concept of climate literacy. Many phenomena in the context of climate change, such as the greenhouse effect, are based on energy related processes. Thus, we assume that for dealing with climate change in education the understanding of the energy concept is essential. Although curricula across the globe have strengthened efforts to support teaching the energy concept, most learners struggle to develop a deep understanding of energy. To examine the current state of research in science education concerning the relationship between the understanding of climate change and the energy concept, we conducted a systematic literature review. This research summarizes and discusses previous findings regarding the extent to which learners use the energy concept to explain the causes and consequences of climate change, whether energy knowledge is a prerequisite for understanding climate change and to what extent knowledge of energy influences the intention to engage in activities to reduce climate change and its impacts.
\end{abstract}

Keywords: climate change, climate literacy, energy, systematic literature review

\section{INTRODUCTION}

Climate change has become one of the most pressing environmental challenges of the last decade. Many ecosystems are vulnerable to changes in climate that have been triggered so far. Ongoing greenhouse gas emissions have most likely induced irreversible changes to physical, biochemical and anthropological systems by shifting the thermal equilibrium state (Pachauri et al., 2015). To address this challenge, it is necessary to understand more than the causes of climate change. People need to be empowered to assess new scientific evidence and understand the consequences of their own actions. These needs are, in addition to understanding of the basic principles of the Earth climate system and the meaningful communication about climate change, key features of climate literacy (U.S. Global Change Research Program, 2009). This literature review intends to contribute to the long-term educational goal to enable citizens not only to understand the climate system but also to make informed decisions for which energy knowledge is necessary. We therefore focus our review on investigating the interrelation of climate literacy with the energy concept.

The energy concept is one of the most important concepts in science education (e.g., Harlen, 2015). It can be differentiated into four basic aspects. These aspects are knowledge of energy transfer, transformation, conservation and degradation (Duit, 2014). In the course of the literature review, it will become clear that all these aspects are closely intertwined with climate literacy. In particular, when considering climate change as a socio-scientific issue, these energy aspects are of importance. This is due to the challenge of finding solution strategies in the context of climate change, where social, ecologic and economic aspects have to be carefully weighed against one another,

(C) 2019 by the authors; licensee Modestum Ltd., UK. This article is an open access article distributed under the terms and conditions of the Creative Commons Attribution License (http://creativecommons.org/licenses/by/4.0/). \Mittenzwei@ipn.uni-kiel.de (*Correspondence) $\square$ Bruckermann@ipn.uni-kiel.de $\square$ Nordine@ipn.uni-kiel.de 凹 Harms@ipn.uni-kiel.de 


\section{Contribution of this paper to the literature}

- In this review, we analysed the state of the art pertaining to the relationship between knowledge of energy and students' understanding of climate change. From a scientific point of view, energy is central for climate change processes. We argue that knowledge of energy is essential to grasp climate change.

- Even though both concepts have been researched intensively in science education, to our knowledge there is no systematic overview integrating respective findings.

- With our literature review we aim to address this gap while providing a baseline for future science education research fostering climate literacy by considering the relevance of energy understanding.

resulting in different possible courses of action, each bringing their own advantages and disadvantages. All potential solutions must prevent the global energy equilibrium state from shifting. Due to the fact that climate change poses a global challenge and therefore includes and considers the interests of various stakeholders, no onedimensional strategies are likely to be successful. Potential solutions must be multidimensional and need to be equally balanced from both an ethical and a normative standpoint. It is especially this ethical and normative reasoning that characterizes socioscientific issues like climate change (Zeidler, Sadler, Simmons, \& Howes, 2005). In recent years, teaching socio-scientific issues in schools has received increasing attention (e.g., Sakschewski, Eggert, Schneider, \& Bögeholz, 2014). The main objective here is to promote scientific literacy (e.g., Sadler, Klostermann, \& Topcu 2011), yet climate change instruction introduces new challenges due to the complexity of the processes involved.

For example, global warming has a complex spatial distribution pattern, affecting different regions and societies in different ways. Great Britain, for example, could experience a relatively moderate rise in temperature during global warming as a result of the weakening of the Atlantic Meridional Overturning Circulation (Liu, Xie, Liu, \& Zhu, 2017), while the Arctic regions have to estimate significant temperature increases (Pachauri and Mayer, 2015). Therefore, if climate change is addressed as a socio-scientific issue, it is not only a question of who is responsible, but also of who is affected and to what extent. From a scientific perspective, explaining these regional patterns of climate change requires learners to possess extensive conceptual background knowledge. For example, the explanation of the greenhouse effect requires at least knowledge of energy forms, energy transfer and energy transformation. In the next section, we begin unpacking the role that the energy concept might play in climate literacy by operationalizing relevant constructs and identifying which energy knowledge is relevant for knowledge of climate change.

\section{RESEARCH QUESTIONS}

Climate change is both a phenomenon in which specific energy processes take place such as the transformation of radiation energy into thermal energy and a phenomenon that can be analysed as a whole by using energy as a balancing quantity like in the climate scenarios. This also corresponds to the energy understanding formulated by the U.S. Framework for K-12 Science Education where the energy concept is listed under both Disciplinary Core Ideas (which focus largely on understanding energy in the context of the physical sciences) and Crosscutting Concepts (which focus on how the flow, cycling, and conservation of energy and matter are used across disciplines) (National Research Council, 2012). Despite teaching of scientifically correct energy knowledge being a major goal of international curricula (e.g., Sakschewski et al., 2014), students often possess insufficient knowledge of energy (e.g., Opitz, Harms, Neumann, Kowalzik, \& Frank, 2015). In addition, learners have difficulties in applying knowledge of energy across disciplinary boundaries, especially in the context of the carbon cycle (You, Marshall, \& Delgado 2017). Accordingly, students often lack essential knowledge for explaining climate change. We are not aware of a systematic examination of whether or how students' understanding of energy ideas taught in school contributes to climate literacy. We therefore conducted a systematic literature review to examine what is already known in science education about the relation between understanding the energy concept and climate literacy. This review is structured according to the following research questions:

1. To what extent is knowledge of energy a prerequisite for the development of knowledge of climate change?

2. To what extent do students use knowledge of energy for explaining the cause and effect of climate change?

3. To what extent can knowledge of energy be conveyed through the context of climate change?

4. To what extent does knowledge of energy influence the intention of taking actions to reduce climate change and its impacts? 


\section{THEORETICAL BACKGROUND}

\section{The Operationalization of Climate Literacy}

This review refers to the operationalization of climate literacy according to the U.S. Global Change Research Program (2009) which, in cooperation with the National Oceanic and Atmospheric Administration (NOAA) and the American Association for the Advancement of Science (AAAS), defines that a climate-literate person is someone who:

understands the essential principles of Earth climate system, knows how to assess scientifically credible information about climate, communicates about climate and climate change in a meaningful way, and is able to make informed and responsible decisions with regard to actions that may affect climate. ( $p .4)$

Climate literacy therefore describes not only knowledge of climate change, but also the ability to analyse climate data and to evaluate and reflect on behaviour. For this reason, this review focus on the extent to which knowledge of energy influences knowledge of climate change and analyses its relationship to climate change related behavioural intentions.

\section{The Operationalization of the Energy Concept}

In the process of analysing the influence of energy knowledge on climate literacy, we distinguish between different knowledge dimensions. In this respect we refer to the operationalization by Krathwohl (2002), according to which knowledge is differentiated into factual knowledge, conceptual knowledge, procedural knowledge and metacognitive knowledge. In particular, we refer to conceptual knowledge, which is defined by knowledge among the relationship of different knowledge elements. The energy concept is an example of conceptual knowledge; it can be used in different contexts to explain phenomena and predict processes.

In science education, the energy concept is traditionally structured into four basic aspects. Knowledge of energy is commonly operationalized as knowledge of energy forms, energy transfer / transformation, conservation and degradation (e.g., Duit, 1984; Neumann et al., 2013). However, in context of climate literacy it is important to distinguish between energy transfer and transformation. In order to explain the spatial distribution patterns of climate change, energy transfer processes are of great importance and when explaining the causes of climate change, energy transformation processes are crucial. Therefore, this review uses the recently modified operationalization of the energy concept by Duit (2014), who has separated the transfer and transformation aspects and eliminated energy forms as a distinct aspect, arguing that energy forms are included within all other aspects of energy. The resulting separate consideration of energy transfer and transformation is important for emphasizing the different relevance of each aspect in relation to climate change.

\section{Deriving the Relevance of Energy Knowledge for Climate Literacy from a Scientific Perspective}

The analysis of the relationship between the energy concept and climate literacy begins by considering, from a scientific perspective, which of the energy aspects should be relevant with regard to knowledge of climate change. In a second step, we consider whether these interrelationships can also be found in the publications of science education. In scientific research on climate change, the energy concept plays only a minor role. One reason for this is that many scientific disciplines are working on climate change. One field of research in which the energy concept plays a greater role is climate modelling, because here energy balance scenarios are often calculated. In this research area, energy is first of all a quantity to account for processes occurring in a system or for comparing different states of a system. In order to predict future climate, it is necessary to forecast greenhouse gas emissions based on various parameters such as the development of the economy or demographic trends, because these parameters shift the energy balance of the Earth's system. These projections are known as climate scenarios.

The newest climate scenarios of the Intergovernmental Panel on Climate Change (IPCC) are based on so called representative concentration pathway scenarios (e.g., Moss et al., 2010). These representative concentration pathways scenarios quantify the change in radiative forcing by the amount of energy per second and square meter that passes through the tropopause. This reduces climate change to a change in the energy balance of the atmosphere, or more precisely to a change in the thermal equilibrium state. Modern climate models, such as the Earth System Model of the Max Planck Institute for Meteorology, use these climate scenarios to calculate changes in the climate system (e.g., Giorgetta et al., 2013). They attempt to describe the energy flows as well as the carbon and water cycles between the atmosphere, land areas and oceans with the highest possible resolution. Climate models make it possible to predict the global temperature rise and allow to derive statements about the development of the regional distribution patterns of climate change. 
With regard to the aforementioned energy aspects, knowledge of energy conservation is required in the context of climate modelling in order to perceive climate change as a shift in the thermal equilibrium state of the atmosphere. The climate system is an open system, in which incoming and outgoing radiation balance each other. Energy transformation processes are slightly less relevant than energy transfer processes in the context of climate modelling. As soon as solar radiation energy reaches the Earth system, the question of its distribution through energy transfers via conduction and convection, as well as the manifestation of the spatial distribution patterns, becomes more crucial. However, knowledge of energy transformation is important to explain the greenhouse effect and why a higher thermal equilibrium state occurs depending on the proportion of reflected and absorbed radiation. Lastly, knowledge of energy degradation helps to understand issues of energy consumption and the associated change in greenhouse gas emissions.

\section{Heuristic Synthesis of the Core Relations between Energy Knowledge and Climate Literacy}

Accordingly, at least from the perspective of climate modelling, energy knowledge should be an important part of climate literacy. Derived from this analysis, the following four guiding hypotheses emerge: (1) Knowledge of energy transformation is necessary to understand the causes of climate change, because the altered atmospheric concentration of greenhouse gases leads to a shift in absorption, emission and reflection of radiation and thermal energy. (2) Knowledge of energy transfer is necessary to understand the origin of the spatial distribution patterns of climate change, because the radiation energy which reaches the earth varies spatially and seasonally and through energy transfer processes such as conduction and convection very complex spatial patterns emerge. (3) Knowledge of energy conservation is necessary to understand climate change as a shift in the thermal equilibrium state, because global warming is not caused by increasing solar radiation energy. In fact, only the energy balance within the Earth system shifts and the total amount of outgoing and incoming energy remain balanced. (4) Knowledge of energy degradation is necessary to understand the consequences of energy consumption in relation to climate change, because with every energy transformation process thermal energy is also dissipated and cannot be used for further energy transformation processes. Although this compilation of connections can undoubtedly be expanded, it should provide a structure to examine whether these major relations are considered in the area of science education.

\section{METHODS}

To investigate the relationship between the energy concept and climate literacy, we conducted a systematic literature review. Our review procedure is derived from the field of medicine and is based on the Handbook for Systematic Reviews of Interventions by the Cochrane Collaboration (Higgins and Green, 2011). Based on this guideline, we systematically identified and selected studies to include in our review. For this purpose, we performed a systematic search using the Education Resources Information Center (ERIC) database. We supplemented this search with the help of the publication database Web of Science in order to reach the widest possible range of publications. In detail, we defined standardized search terms which illuminate the intersection between the research areas of climate change and energy. These search terms were then combined into search statements using diverse operators and parameters. A complete list of search statements and the corresponding number of publications can be found in Table 1. 
Table 1. List of search statements

\begin{tabular}{|c|c|c|}
\hline Database & Search statement & $\mathbf{n}$ \\
\hline ERIC & +abstract:"energy" AND + abstract:"climate change" & 138 \\
\hline ERIC & +title:"energy" AND +title:"climate change" & 3 \\
\hline ERIC & "carbon cycle" AND descriptor:energy & 7 \\
\hline ERIC & energy AND descriptor:"carbon cycle" & 0 \\
\hline ERIC & "carbon cycling" AND descriptor:energy & 1 \\
\hline ERIC & energy AND descriptor:"carbon cycling" & 0 \\
\hline ERIC & "climate change" AND descriptor: energy & 136 \\
\hline ERIC & energy AND descriptor:"climate change" & 11 \\
\hline ERIC & "global warming" AND descriptor:energy & 73 \\
\hline ERIC & energy AND descriptor:"global warming" & 9 \\
\hline ERIC & "greenhouse effect" AND descriptor:energy & 30 \\
\hline ERIC & energy AND descriptor:"greenhouse effect" & 9 \\
\hline ERIC & "learning progression" descriptor:"climate change" & 0 \\
\hline ERIC & +title:"climate change" AND "learning progression" & 3 \\
\hline ERIC & "learning progression" descriptor:"global warming" & 0 \\
\hline ERIC & +title:"global warming" AND "learning progression" & 0 \\
\hline ERIC & "learning progression" descriptor:"carbon cycle" & 0 \\
\hline ERIC & +title:"carbon cycle" AND "learning progression" & 0 \\
\hline ERIC & "learning progression" descriptor:carbon cycling" & 0 \\
\hline ERIC & +title:"carbon cycling" AND "learning progression" & 2 \\
\hline Web of Science & $\mathrm{TS}=(($ global warming $)$ AND energy $)$ AND SU=EDUCATION EDUCATIONAL RESEARCH & 21 \\
\hline Web of Science & $\mathrm{TI}=$ (global warming) AND TS=energy AND SU=EDUCATION EDUCATIONAL RESEARCH & 4 \\
\hline Web of Science & $\mathrm{TI}=$ energy $\mathrm{AND} T \mathrm{TS}=$ (global warming) $\mathrm{AND} \mathrm{SU}=\mathrm{EDUCATION}$ EDUCATIONAL RESEARCH & 4 \\
\hline Web of Science & $\mathrm{TS}=(($ climate change) $\mathrm{AND}$ energy) AND SU=EDUCATION EDUCATIONAL RESEARCH & 53 \\
\hline Web of Science & $\mathrm{TI}=$ (climate change) AND TS=energy AND SU=EDUCATION EDUCATIONAL RESEARCH & 13 \\
\hline Web of Science & $\mathrm{TI}=$ energy AND TS=(climate change) AND SU=EDUCATION EDUCATIONAL RESEARCH & 8 \\
\hline Web of Science & $\mathrm{TS}=(($ carbon cycle) AND energy) AND SU=EDUCATION EDUCATIONAL RESEARCH & 13 \\
\hline Web of Science & $\mathrm{TI}=$ (carbon cycle) AND TS=energy AND SU=EDUCATION EDUCATIONAL RESEARCH & 1 \\
\hline Web of Science & $\mathrm{TI}=$ energy AND TS=(carbon cycle) AND SU=EDUCATION EDUCATIONAL RESEARCH & 4 \\
\hline Web of Science & TS $=(($ carbon cycling) AND energy) AND SU=EDUCATION EDUCATIONAL RESEARCH & 13 \\
\hline Web of Science & $\mathrm{TI}=$ (carbon cycling) AND TS=energy AND SU=EDUCATION EDUCATIONAL RESEARCH & 1 \\
\hline Web of Science & $\mathrm{TI}=$ energy AND TS=(carbon cycling) AND SU=EDUCATION EDUCATIONAL RESEARCH & 4 \\
\hline Web of Science & $\mathrm{TS}=(($ greenhouse effect) AND energy $)$ AND SU=EDUCATION EDUCATIONAL RESEARCH & 17 \\
\hline Web of Science & $\mathrm{TI}=$ (greenhouse effect) AND TS=energy AND SU=EDUCATION EDUCATIONAL RESEARCH & 7 \\
\hline Web of Science & $\mathrm{TI}=$ energy AND TS=(greenhouse effect) AND SU=EDUCATION EDUCATIONAL RESEARCH & 3 \\
\hline Web of Science & $\mathrm{TS}=(($ learning progression) AND (climate change) $)$ AND SU=EDUCATION EDUCATIONAL RESEARCH & 12 \\
\hline Web of Science & $\mathrm{TS}=(($ learning progression) AND (global warming)) AND SU=EDUCATION EDUCATIONAL RESEARCH & 1 \\
\hline Web of Science & TS $=(($ learning progression) AND (carbon cycling) $)$ AND SU=EDUCATION EDUCATIONAL RESEARCH & 8 \\
\hline Web of Science & TS $=(($ learning progression) AND (carbon cycle) ) AND SU=EDUCATION EDUCATIONAL RESEARCH & 8 \\
\hline Total & & 617 \\
\hline
\end{tabular}

After the database search initially returned 617 publications, we successively sorted out articles that were not peer reviewed, duplicates and studies that did not correspond to the research questions. The complete analysis of the articles, including articles added by the screening of the bibliographies, ultimately led to the inclusion of 78 studies. These studies were then systematically evaluated using the critical review form for qualitative studies (Law, Stewart, Letts, Pollock, Bosch, and Westmorland, 1998). In addition, further background literature was taken into account for fundamental aspects. To report the processes of identification and the selection of studies we used the PRISMA statement (see Figure 1). The PRISMA Statement (Preferred Reporting Items for Systematic Reviews and Meta-Analyses) is a minimum standard for reporting systematic reviews and meta-analyses (Moher et al., 2009). 


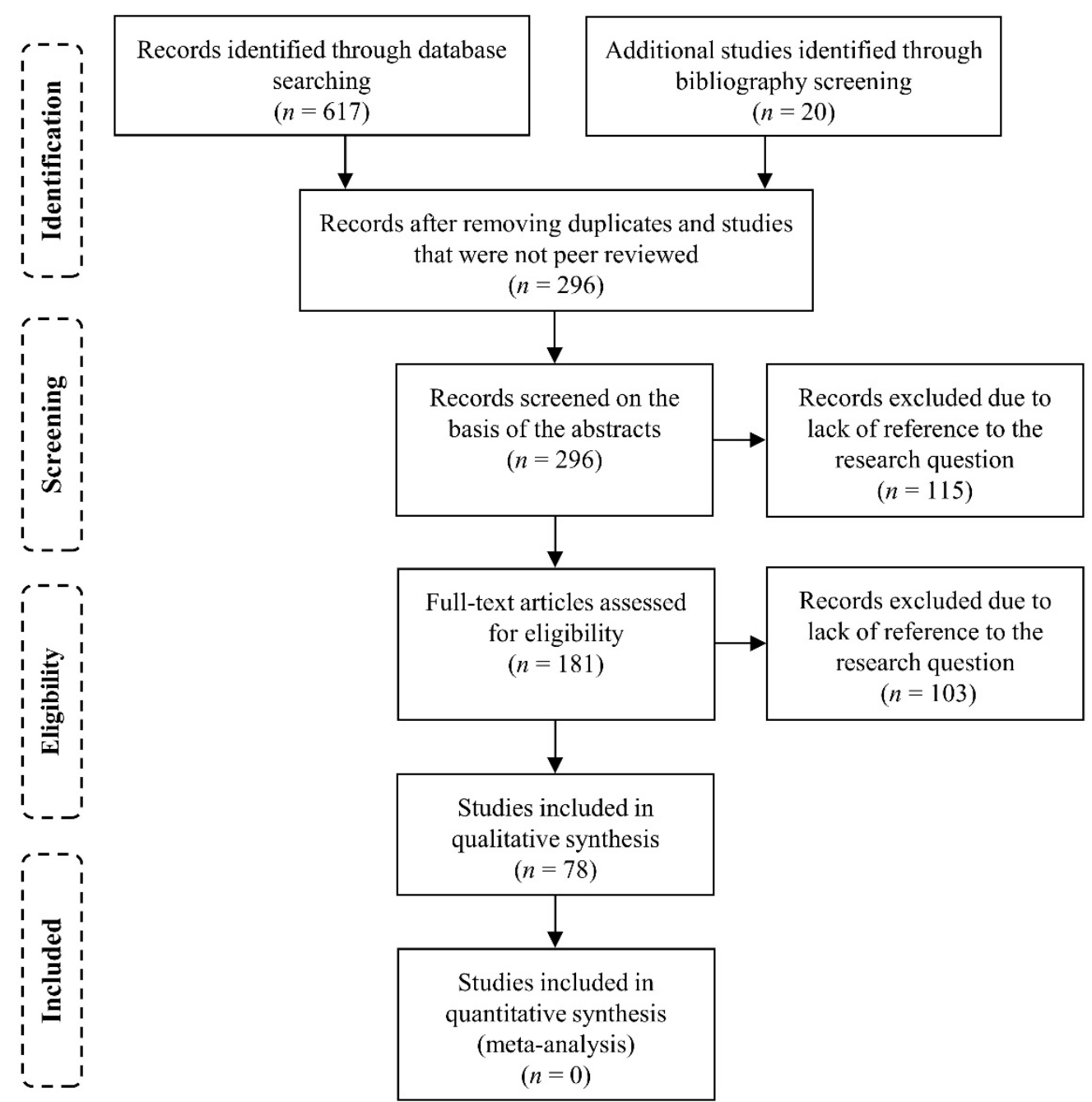

Figure 1. Flow diagram of literature search and selection according to PRISMA (see Moher et al., 2009)

In total, we analysed 20 qualitative studies, 15 intervention studies, 12 quantitative studies, 26 mixed method studies and 5 reviews. The analysis included altogether 33,997 test persons of all age groups. Approximately 25 percent of studies on the interrelations of the energy concept and climate literacy have mainly addressed energyrelated alternative conceptions about climate change. Another 20 percent of the studies examined the relationship between knowledge of energy and climate change as well as the influence of energy knowledge on climate change related behaviour. However, the studies in these two thematic areas sometimes contained only peripheral references to the research questions or addressed only a specific aspect of them. The same applies to studies on teaching approaches about energy and climate change, as well as on knowledge of energy consumption and climate change, which were relatively common with 9 and 15 percent, respectively. About 10 percent of the studies investigated learning progressions about the carbon cycle, which contained substantial references to the energy concept.

\section{RESULTS}

We organise our results into two main sections. The first section examines the relationship between knowledge of energy and climate change, and the second section investigates the influence of energy knowledge on climate change related behavioural intention. These two sections do not represent all of the overlaps between the energy concept and climate change, but they represent the most relevant connections to climate literacy. Research question 2 (To what extent do students use the energy concept to explain climate change?) is addressed in both sections. On the one hand it is relevant for examining the relationship between knowledge of energy and climate change, whether students use the energy concept for explaining climate change, and on the other hand it is important in the context of behaviour, whether students take energy aspects into account when making action decisions. Research question 3 (To what extent can knowledge of energy be conveyed through the context of climate change?) 
could only be investigated to a limited extent because, as of now, there are only few studies tackling this question. Therefore, we address it exclusively in our discussion.

\section{Energy Knowledge as a Prerequisite for Understanding Climate Change}

Although the relationship between the energy concept and knowledge of climate change is apparent from a scientific perspective, only a few existing studies have directly investigated this relationship in context of science education. Besson and Ambrosis (2013), for instance, have developed an energy-related instructional intervention focused on the topics of the greenhouse effect and global warming. In their investigation, they were able to show that the energy concept is rarely used by students and student teachers to explain the causes of climate change. Only 6 percent of the student teachers and 9 percent of the high school students could adequately explain the greenhouse effect by using the energy concept based on absorption and emission of radiation. This problem was also confirmed in investigations by Frappart, Moine, Jmel, and Megalakaki (2018) and Shepardson, Niyogi, Choi and Charusombat (2009). Since it is difficult to show the relationship between knowledge of energy and the greenhouse effect when the participants show little knowledge of energy, they developed an intervention in which they foster energy knowledge that is related to climate change. This knowledge included the concepts of heat, radiation, temperature, internal energy and the thermal equilibrium state.

Besson and Ambrosis (2013) were subsequently able to show that their instructional intervention promotes knowledge of energy. Additionally, they refer to two of the above-mentioned guiding hypotheses by addressing energy conservation and transformation in relation to climate change. Regarding the energy aspect of conservation, they were able to show that only 13 percent of the participants in the pre-test could explain the temperature of a body as a thermal equilibrium state, which results from the sum of incoming and outgoing radiation. With the help of the intervention, 59 percent of the participants in the post-test were able to construct arguments using the concept of the thermal equilibrium state. With regard to the aspect of energy transformation, the proportion of participants who understood the greenhouse effect in terms of the absorption of solar and the emission of thermal radiation increased from 17 to 57 percent during the intervention. However, many respondents maintained the alternative conception that the sun's rays were trapped in the atmosphere.

This study suggests that the conducted intervention promotes knowledge of energy in context of climate change and that the participants use more often the aspects of energy transformations and energy conservation to explain the causes of climate change. Unfortunately, the data set was not evaluated in regards to whether the respondents who had difficulties in understanding the concept of the thermal equilibrium state were primarily affected by the alternative conception of trapped sunrays. It is likely that the aspects of energy transformation and energy conservation are interacting with each other in connection with climate literacy. Nevertheless, the study was able to show that by promoting energy knowledge, students' ability to explain climate change and its cause increased.

Further important conclusions on the link between knowledge of energy and climate change can be found in the results of Svihla and Linn (2012) and Visintainer and Linn (2015), who investigated in an intervention study, based on the knowledge integration framework (Linn, Bell, and Davis, 2004), to what extent the energy concept is taken into account when explaining climate change. In this context, they were able to show that students who understood the process of energy transformation from solar to thermal radiation and the interaction between infrared radiation and greenhouse gases developed more elaborate knowledge of the greenhouse effect. In addition, they were able to show that a normative understanding of the greenhouse effect helps learners to integrate their knowledge of the human influence of energy use. Therefore, it seems that there is an interaction between knowledge of energy transformations and the understanding of the anthropogenic greenhouse effect. However, the sample was small and consisted of students from a sixth grade who still have little understanding of the energy concept.

Another approach towards integrating energy knowledge in context of climate change was taken by Puttick, and Tucker-Raymond (2018). In their intervention study, they used the visual programming environment Scratch to have girls create simulations in context of climate change with a focus on system and computational thinking. During the course of the intervention, the participants were able to integrate different system components with each other and link more often energy consumption with the greenhouse effect and global warming. However, the qualitative evaluation shows a problem that is symptomatic of many publications regarding interventions in the context of climate change (e.g., Aksüt, Dogan, \& Bahar, 2016; Mazze, \& Stockard, 2013): the participants simply describe a correlative relationship between energy consumption, greenhouse effect and the imbalance of the carbon cycle. It does not become apparent, whether the participants can separate energy transforming processes from matter cycles. Furthermore, it is also unclear whether the participants understand that the increased greenhouse gas concentrations alters the global energy transfer and transformation processes.

So far, the aforementioned publications are among the few studies that deal explicitly with the relationship between knowledge of energy and climate change. Although they have not addressed all the previously predicted interrelationships, they do address two main hypotheses: that knowledge of energy transformation is relevant 
when explaining the greenhouse effect and that the energetic equilibrium state is one of the greatest challenges for learners in the context of climate change. Remarkably, both aspects are taken up in other sub-areas of science education research. The aspect of energy transformation is addressed in detail in the research on learning progressions and the energetic equilibrium state is taken up in the research on alternative conceptions. The results of both research areas are described in the following sections.

\section{Energy-related alternative conceptions in the context of climate literacy}

Learners develop alternative conceptions of scientific phenomena based on their own experiences in their everyday lives (e.g., Duit, 1991). To address the question whether knowledge of energy and climate change are interrelated, alternative concepts could give us an indication of where learners have still insufficient knowledge of scientific concepts and substituted them with their own conceptions. Most of today's studies on alternative conceptions in the context of climate change are based on Boyes and Stanisstreet's work from the 1990s. In the following years, various authors further categorised and differentiated these alternative conceptions. In this context, age differences as well as the fact that specific alternative conceptions occur over time in a changed frequency were also taken into account.

Especially, alternative conceptions relating to energy knowledge in context of climate change that are described in the literature, are about the causes of climate change. Boyes and Stanisstreet (1993) were able to show that students often assume that the greenhouse effect is caused by an increase in solar radiation. The most common energy-related alternative conceptions are that more solar radiation enters the Earth system through the ozone hole or that less solar radiation can leave the atmosphere. Niebert and Gropengießer (2014) differentiated these alternative conceptions into warming by higher energy input and warming by less energy output. The authors were additionally able to show that for secondary school students in particular the thermal equilibrium state represents a major learning obstacle. The change in absorption and reflection of solar radiation due to the increase of the greenhouse gas concentrations is mainly understood as an imbalance which increases the temperature, without considering that the energy input and output remain constant once a new thermal equilibrium is reached. This perception interferes with secondary students' understanding climate change in terms of a shift in the thermal equilibrium state of the atmosphere. Besides these fundamental alternative conceptions, there are some minor energy-related alternative conceptions about the cause of climate change, such as the assumption that global warming is caused by radioactivity (Boyes \& Stanisstreet, 1993; K1lınç, Boyes, \& Stanisstreet, 2013).

In addition to the cause of climate change, there are some energy-related alternative conceptions about possible solution strategies to reduce climate change and its consequences. For example, a considerable proportion of younger students were unsure whether saving electrical energy or using renewable energy sources is affecting climate change (Boyes \& Stanisstreet, 1993). It could be argued that these pupils may find energy saving and the use of renewable energy ineffective. In fact, Boyes, Skamp, and Stanisstreet (2008) were able to show that less than half of their examined middle school students considered energy saving to be an ineffective strategy in reducing the impacts of climate change. However, Avramides, Craft, and Luckin $(2013,2016)$ were able to show that, when looking at human energy consumption, pupils take primarily the direct rather than indirect consumption of energy into account. As a result, the influence of certain energy-related actions on climate change can be misjudged. However, how many learners underestimated or actually misunderstood the influence of energy consumption on climate change cannot be conclusively determined on the foundation of the available studies.

Aside from alternative concepts about the causes and consequences of climate change, it is important to note that energy-related alternative conceptions have gradually changed over the last decades. For example, Hanson (2010) found that the ratio of students who confuse the greenhouse effect and ozone hole issue has increased significantly in Norway since the 1990s. Hanson assumes that many reasons could have contributed to this, including the temporal occurrence of these two phenomena in the media and the overgeneralisation of environmental problems by students.

Furthermore, there is a negative correlation between the occurrence of certain energy-related alternative conceptions and age. With increasing age, the proportion of energy-related alternative conceptions generally decreases. For example, the alternative conception that radioactivity effects climate change significantly decreases during middle school (Boyes \& Stanisstreet, 1993). This can possibly be explained by an increase in knowledge and its integration. As mentioned before, young pupils often overgeneralise environmental problems. They struggle to differentiate which environmentally harmful substances or behaviours affect which environmental problem.

However, there are also energy-related alternative conceptions that occur more often with increasing age. The alternative conception that climate change is caused by solar radiation being unable to leave the atmosphere has been found to increase during middle school (Boyes \& Stanisstreet, 1993). Different attempts were made to investigate the cause of the emergence of this alternative concept. One approach is to investigate how illustrations and analogies in textbooks may promote this alternative conception. Chao, Chou, Yen, and Chen (2017) were able 
to show that students' knowledge about greenhouse gases and the absorption and reflexion of radiation varies depending on the textbook used in school. The authors demonstrated that the analogy of a greenhouse and illustrations of the greenhouse effect with the help of a thin layer of greenhouse gases promote the alternative conceptions that solar radiation is held back by a thin layer of greenhouse gases in the atmosphere. The problem is that these analogies and figures take neither the aspect of energy transformation nor the interaction with molecules into account. Without any model reflection, this image remains in the students' perception. Therefore, textbooks can trigger the energy-related alternative conception that climate change is caused by solar radiation being unable to leave the atmosphere. However, this can only explain the appearance of this alternative concept to a limited extent. It is also possible that the molecular level of abstraction and the energy related processes like the thermal equilibrium state are too difficult for lower middle school students. A firm conclusion that explains the changed frequency over time cannot be made at this point.

\section{Learning progressions on energy knowledge in the context of climate literacy}

In order to prepare learners for dealing with socio-scientific issues, science education focuses on core concepts of science and their development (e.g., National Research Council, 2012). In this regard, many research articles on learning progressions have currently been published (e.g., Chen \& Anderson, 2015; Breslyn, McGinnis, McDonald, \& Hestness, 2016). Learning progressions describe the increasingly sophisticated knowledge of core concepts that are, for example, needed for a better understanding of socio-scientific issues. Learning progressions can have a significant impact on curriculum development if they represent cognitive models of students' learning development (e.g., Alonzo \& Gotwals, 2012). With regard to the question of whether knowledge of energy and climate change are interrelated, respective research reveals the level at which the understanding of energy knowledge becomes relevant in the context of climate change and the number of learners that attain said level of understanding.

Studies on learning progressions of energy knowledge in the context of climate literacy mainly address carbon cycles (Chen \& Anderson, 2015; Jin \& Anderson, 2012; Jin, Zhan, \& Anderson, 2013; Mohan, Chen, \& Anderson, 2009; Parker, los Santos, \& Anderson, 2015; Schramm, Jin, Keeling, Johnson, \& Shin 2018). Four achievement levels were distinguished and found with minor differences in all investigations. The lower anchor of the learning progressions begins at the macroscopic abstraction level. Carbon transforming processes are perceived to have a purpose and are initiated by actors with specific needs. At the second achievement level, learners consider different products and educts. Energy is understood as a necessity to enable processes, but energy sources cannot always be identified. At the third achievement level, carbon transformation processes can be analysed at a molecular abstraction level. The transformation of matter in cellular processes can be described and even small molecules such as ATP are recognized as energy sources. The upper anchor of the learning progressions is characterized by the ability to trace energy transformation processes independently from matter. As a result, the energy aspect of degradation can be taken into account and energy transformation processes are no longer perceived as renewing in the carbon cycle. The research results of the considered learning progression can be summarized by the challenge that learners have difficulties with the molecular level of abstraction, as well as with analysing energy transformation processes independently from matter in carbon cycles. The latter was confirmed once again by Zangori, Peel, Kinslow, Friedrichsen, and Sadler (2017), who have analysed the cross-disciplinary model-based reasoning about carbon cycling and climate change.

Similar results were found in learning progressions on climate change. Breslyn, McGinnis, McDonald, and Hestness (2016) for instance have investigated a learning progression on the topic of sea level rise. Here as well, the molecular level of abstraction in connection with the energetic process of thermal expansion confronts learners with substantial learning barriers. In addition, Breslyn, Drewes, McGinnis, Hestness, and Mouza (2017) were able to show, in the context of a learning progression on climate change, that higher levels of understanding require knowledge of energy balancing and McGinnis, Breslyn, McDonald, and Hestness (2017) argue in the context of a hypothetical learning progressions on the urban heat island effect, that higher levels of understanding are accompanied with knowledge of energy transfer and transformation through different materials. However, Breslyn et al. (2017) do not use the perspective of energy conservation, but instead refer only to the imbalance of matter in the carbon cycle and McGinnis et al. (2017) derive their learning progression only hypothetically. Nevertheless, the results of the learning progressions are similar to those in the context of the carbon cycles.

In the context of climate change, a major problem is that only a small proportion of learners reach third and fourth achievements levels identified by Jin and Anderson (2012). Even in highschool, only 10 percent of the respondents were able to use the energy concept as a tool for analysing carbon cycles and about half of the respondents were unable to exceed the second achievement level. A key challenge in developing climate literacy is that many arguments and counterarguments in context of the debate about climate change require the fourth achievement level (Mohan, Chen, \& Anderson, 2009). Hokayem and Gotwals (2016) also conclude in their learning progression on ecological systemic reasoning that energy is only used in the highest level of complex causal 
reasoning. With regard to our guiding hypotheses, this mainly relates to the cause of climate change and the consequences of energy consumption. Every time fossil fuels are burned or anabolic processes proceed, there is a conversion of matter in the carbon cycle. The imbalance of these processes leads to an altered concentration of greenhouse gases and to a change in the ratio of the absorption and reflection of solar radiation. Notwithstanding the outlined research results about energy knowledge in the context of carbon cycles, we cannot yet derive a causal connection between knowledge of energy and an elaborate understanding of climate change. Yet, it is striking that an elaborate understanding of carbon cycles appears to go along with the ability to use energy as an analytical tool and to trace energy independently from matter. Learners who do not reach the upper anchor of the considered learning progressions repeatedly understood energy to be reused like carbon in a cycle. This perception stands in contrast to the aspect of energy degradation.

The question arises whether the lack of knowledge of energy degradation hinders learners' ability to understand climate change. This question is closely related to the definition of climate literacy. To understand the cause of climate change, it is particularly necessary to understand the aspect of matter transformation in carbon cycles. It is the imbalance between the fixation and emission of carbon dioxide and the transfer and transformation of energy during interaction with matter that explain the cause of climate change. The proportion of thermal energy that dissipates is in contrast negligible in terms of the energy balance of the Earth system. However, if climate change is regarded as a socio-scientific issue, it is important that when fossil energy sources are burned, a part of the energy is degraded. The importance of knowledge of energy degradation therefore depends on whether only the cause of climate change is considered or the overall social interactions.

\section{Conclusions about the relation of knowledge of energy and knowledge of climate change}

To summarize the relationship between knowledge of energy and climate change, we can conclude that knowledge of energy is only insufficiently used by students to explain climate change. Furthermore, we observe that there are a large number of energy-related alternative conceptions with regard to climate change. Many of these alternative concepts refer to the greenhouse effect, because this sub-component of climate change has many energetic implications. The greatest challenge seems to be the understanding of the thermal equilibrium state. For an elaborate understanding of this sub-process of climate change, it is necessary to integrate knowledge of all energy aspects. However, previous research has predominantly been limited to describing alternative conceptions without investigating their causes. At this point, we can only formulate hypotheses about the causes of alternative conceptions. However, if students assume that climate change is caused by increased solar radiation, it is quite likely that they have not understood the thermal equilibrium state. Likewise, if students assume that sun rays are held in the atmosphere, it is quite likely that they are not adequately familiar with the energy aspect of transformation. The results of this literature reviews so far suggest, that these hypotheses likely hold true. However, in order to develop teaching interventions, this connection must be empirically verified.

Additionally, one energy-related alternative conception regarding climate change has not yet been sufficiently described. Leiserowitz et al. (2010) were able to show that more than half of the study participants held the alternative conception that the increase in the mean temperature on Earth will be the same all over the world. This energy-related alternative conception is particularly relevant when climate change is considered to be a socioscientific issue. In this context, it is important to understand that the regions that mainly caused climate change are not necessarily the ones that are most affected. Here too, the aim of the research community is not simply to remain on a descriptive level, but to find the cause of this alternative conception. The origin of the spatial distribution patterns of climate change is based on different energy transfer processes. Convection, conduction and latent heat flows ultimately describe the transfer of energy. People unfamiliar with these processes will most likely also have difficulty understanding why the increase in temperature is not the same across the world, but this assumption has yet to be investigated.

With regard to learning progressions in the context of energy in carbon cycles, the molecular level of abstraction and tracing energy independently from matter are particular challenging for students. The greatest challenge here is that energy is perceived as substance-like and that it is circulating in the carbon cycle. This perception leads to the misunderstanding that energy is being renewed, which stands in contrast to the process of energy degradation and hinders the understanding of problems arising from energy consumption. Whether this perception affects the understanding of climate change depends on the definition of climate literacy. For the greenhouse effect itself, it is more important to understand the matter transformation in the carbon cycle and how the resulting greenhouse gas molecules interact with solar and thermal radiation. For addressing climate change as a socio-scientific issue and make informed decisions, however, the energy aspect of degradation is important, because this issue is strongly related to the finite nature and non-reusability of fossil fuels.

With regard to our above-mentioned guiding hypotheses, it can be summarised that the predicted interrelations between knowledge of energy and knowledge of climate change are only partially addressed in the science education literature. The most obvious connection is that knowledge of energy transformation is necessary to 
understand the greenhouse effect. However, the interrelationships between energy transfer and the spatial distribution patterns, energy conservation and the thermal equilibrium state as well as between energy degradation and the consequences of energy consumption was only examined to a limited extent in the literature.

\section{Knowledge of Energy and its Impact on Behaviour in the Context of Climate Change}

In addition to knowledge of climate change, knowledge of energy also has an impact on climate change related behaviour. The ability to conduct and reflect on behaviour that may affect climate is a significant aspect of climate literacy (U.S. Global Change Research Program, 2009). However, promoting behaviour or informed decisionmaking is a great challenge. Although one might assume that there is a significant relationship between scientific knowledge and informed decision-making regarding socio-scientific issues like climate change, the research results are not that obvious.

Students often lack conceptual knowledge and show multiple alternative conceptions when explaining climate change. Sakschewski et al. (2014) conclude that prior knowledge influences socio-scientific reasoning and decisionmaking competences on energy-related socio-scientific issues. Jho, Yoon, and Kim (2014), disputed whether content knowledge or conceptual knowledge has a greater influence on decision-making processes. A meta-analysis by Allum, Sturgis, Tabourazi, and Brunton-Smith (2008) concludes that there is only a weak relationship between general scientific knowledge and a persons' attitude towards socio-scientific issues (SSIs). However, the strength of this relationship varies depending on the particular socio-scientific issue and the content knowledge that is related to the regarded SSI. The attitude towards genetically modified foods, for example, depends more intensely on conceptual knowledge of genetics.

In addition to prior knowledge, decision-making and the intention to act in the context of climate change is also influenced by affective factors such as attitudes and value attribution (e.g., Dietz, Dan, \& Shwom, 2007; Zaval \& Cornwell, 2017). For example, Jho et al. (2014) investigated the relationship of scientific knowledge, attitudes, and decision-making processes in the context of nuclear power. During the intervention, content knowledge and conceptual knowledge improved significantly, while the attitudes towards nuclear power remained constant. At least when addressing nuclear energy, affective factors seemed to play a decisive role in the process of decisionmaking.

Likewise, in connection with climate change, the relationship between climate literacy and informed reasoning is not as clear as one might assume. It has been found that only half of the American population believes in anthropogenically induced global warming (Leiserowitz, Maibach, Roser-Renouf, Feinberg, \& Rosenthal, 2015) and only a small amount of the American population has sufficient knowledge of climate change (Leiserowitz et al., 2010). However, a causal link between the lack of knowledge and the lack of acceptance of the man-made induced climate change cannot be easily established. Guy et al. (2014) summarized the debate in social sciences towards this topic, by pointing out the impact of political ideologies, the lack of confidence towards the political elite, the spreading of misinformation and conflicting cultural values.

According to Kahan et al. (2012), political ideologies have a stronger influence on the attitudes towards climate change than knowledge. They described that egalitarian communitarians are more concerned about climate change than hierarchical individualists. Guy et al. (2014) supplement that the scepticism against climate change increases with the number of people who are identifying themselves with political conservative parties and free-market economies. However, most studies understate the influence of climate literacy on attitudes towards climate change. Kahan et al. (2012), for instance, mainly considered only general knowledge of science instead of specific knowledge of climate change. Guy et al. (2014) criticize that the aforementioned study only took general knowledge of science into account and were able to demonstrate a positive correlation between specific knowledge of climate change and climate change beliefs. Even more interesting is that Guy et al. (2014) discovered that specific knowledge of climate change seems to weaken the negative effects of individualistic ideologies. Nevertheless, factors such as political ideologies and religious beliefs have a great influence. Bedford (2015) integrates the findings of Kahan et al. (2012) and Guy et al. (2014) by setting up the hypothesis that higher education and general scientific knowledge might help individuals to find arguments for their respective political views. Therefore, specific knowledge of climate change must be developed in school in order to address alternative conception and even some rejecting beliefs.

\section{Efficacy knowledge of energy-related behaviour in the context of climate change}

As described in the previous section, specific knowledge of climate change seems to have an influence on students' attitudes towards climate change. Part of this specific knowledge is efficacy knowledge which, in the context of climate change, means knowledge of whether and to what extent a certain behaviour has an impact on climate change. Since measuring direct behavioural observations is more time-consuming and measuring the efficacy of behaviour in context of climate change is difficult to quantify, many studies have investigated the 
intention to act in relation to the believed usefulness of an action (Ambusaidi et al., 2012b, 2012a; Boyes et al., 2008; Kılınç et al., 2013, 2010; Kılınç, Stanisstreet, \& Boyes, 2008b).

The results of the aforementioned studies on efficacy knowledge can be summarized as follows: the higher the believed usefulness of a certain energy-related behavior is, the higher is the willingness to act. These results were largely confirmed in all sampled countries. For example, students from Australia, Turkey and Oman show a high willingness to act for simple energy-saving behavior and the willingness to act increases with the increasing belief in usefulness of this behavior (Ambusaidi et al., 2012b; Boyes et al., 2008; Kılınç et al., 2010). The same relationship applies to behavior with high opportunity costs such as the use of nuclear energy sources (Boyes et al., 2008). The willingness to act increases with the increasing belief in usefulness of this behavior. However, the willingness to use nuclear energy sources is significantly lower than it is in the case of simple energy-saving behavior and increases only slightly with increasing efficacy knowledge. This is partly due to the high opportunity costs and the possible risks of using nuclear energy. With regard to country-specific differences, it can be observed, that the willingness to use nuclear energy is considerably higher in Turkey than it is in Australia (Boyes et al., 2008; Kılınç et al., 2010).

Subsequently, Boyes et al. (2008) quantified from the difference of the natural willingness and natural reluctance to act the potential effect of education on the respective actions. The higher the gradual difference between the natural willingness and reluctance of an action is, the higher is the probability of influencing the intention to act by imparting efficacy knowledge of energy-related behavior. The difference between the natural willingness and reluctance to act varies between the sampled countries. For example, the potential effect of education on renewable energy use is significantly higher in Australia than it is in Oman or Turkey. On the other hand, the potential effect of education in relation to using nuclear energy is roughly the same in all the countries studied (Ambusaidi et al., 2012b; Boyes et al., 2008; Kılınç et al., 2010).

A further study on efficacy knowledge has been conducted by Christensen and Knezek (2018). Their research is derived from the theory of planned behavior and is based on the assumption that hands-on active learning can promote climate change related behavior. Based on this assumption, a three-week intervention on energy monitoring was carried out with a large sample in the US. The authors found that behavioural intentions and beliefs regarding climate change correlate positively with the energy monitoring activities. However, the authors could not state a precise causal relationship, but it is quite plausible that the efficacy knowledge of the energy-related behavior increases during the energy monitoring activities and this could have increased the behavioral intentions. But this link was not directly examined.

\section{Knowledge of energy and its relation to climate change related risk perception}

Besides efficacy knowledge, the construct of risk perception might also have an influence on energy-related behaviour in the context of climate change. According to Lee, Markowitz, Howe, Ko, and Leiserowitz (2015), the awareness of climate change, regardless of whether it is anthropogenically induced or not, ranges from over 75 percent in western industrialized countries to less than 30 percent in some developing countries. A large share of people who are aware of climate change, however, did not consider climate change a serious threat. Worldwide, the level of education and the belief in anthropogenic climate change are the main predictors for climate change awareness and risk perception.

In China, for example, climate change awareness depends mainly on education, geographic location and household income (Lee et al., 2015). Interestingly, the risk perception of the Chinese people is also increasing in dependence on whether they believe in a human-made climate change and if they are dissatisfied with the local air quality. In some African and Asian countries, the local temperature change is the strongest predictor for climate change related risk perception. Apart from the fact that the association of air quality with climate change is a typical alternative conception, climate change related risk perception seems above all to depend on the experience of a persons' own vulnerability and the level of education. Lee et al. (2015) summarize that education can help to increase climate change awareness and risk perception.

The question now arises how education could promote awareness, risk perception and social participation for climate change. As described above, the attitudes towards socio-scientific issues are affected by specific knowledge that is directly related to the respective SSI. Risk perception is also influenced by specific knowledge. Aksit, McNeal, Gold, Libarkin, and Harris (2017) have shown that climate change related content knowledge influences the risk perception of students. They found that during a semester-long geosciences course, students' knowledge of climate change and risk perception has increased significantly. Energy knowledge as part of climate literacy could also have an impact on risk perception. In the theoretical background, we hypothesized that knowledge of energy transfer is probably necessary to explain the emergence of the spatial distribution patterns of climate change, because the processes responsible for this (e.g., conduction and convection) are basically energy transfer processes. 
In the section about alternative conceptions we argued that the belief, that the increase in the mean temperature on Earth will be the same all over the world is an energy-related alternative conception.

But what is the relationship between risk perception and climate change related behaviour? Regarding to the Integrated Action Model developed by Martens and Rost (1998), risk perception plays a major role in the development of the motivation in context of environmental behaviour, which itself influences the intention to act and volition. The model distinguishes between the severity and probability of a risk. This means that the motivation to act can be low, although climate change is perceived as threatening if the chance of occurring is assessed to be low. The severity and probability of climate change related risks vary considerably and depend on the respective region the student is from and on the manifestation of the spatial distribution patterns of climate change (Pachauri and Mayer, 2015). Tropical storms like hurricanes, for example, only occur in certain regions when specific temperatures are exceeded. Thus, in order to understand the occurrence of climate change related risks, we need knowledge of the origin of the spatial distribution patterns of climate change and, for this purpose, knowledge of energy transfer.

\section{Conclusions about knowledge of energy and its relation to behaviour in the context of climate change}

So far, findings on the relationship between knowledge of energy and behaviour in the context of climate change remain unclear. It has been found consistently that knowledge is not the only predictor of climate change related behaviour, but that many affective components, such as political attitudes and religious beliefs, have an influence (e.g., Dietz et al., 2007; Guy et al., 2014; Kahan et al., 2012). So far, only the connection between the intention to act and the believed usefulness of an energy-related behaviour has been the subject of significant investigation. Apart from the fact that the analyzed studies assessed the intention to act rather than actual behavior, it has also been found that the relation between the intention to act and the believed usefulness varies depending on the respective behavior (e.g., Ambusaidi et al., 2012a; Boyes et al., 2008; K1lınç et al., 2013). This affirms that affective factors have a considerable influence in energy-related behaviour. Beyond that, there is a substantial gap between one's intentions to act and the actual manifestation of a behaviour. Nevertheless, the importance of efficacy knowledge on behaviour should not be underestimated and should be further investigated.

It is likely that the influence of knowledge on attitudes and behaviour towards climate change increases the more specific it becomes. In this context, knowledge of the origins of climate change related risks could be important. As derived earlier from the literature, it makes sense to consider the perception that the increase in temperature is about the same all over the world, as an energy-related alternative conception. This alternative perception often occurs. The spatial distribution pattern of climate change and thus the distribution of possible risks is ultimately based on energy transfer processes such as convection, conduction and latent heat transfer. If knowledge of these processes is absent and if the impacts of climate change are not differentiated on a regional scale, an incorrect assessment of one's own risk is likely. From the area of health and sustainability education, however, it is well-known that the risk assessment can influence the intention to act (e.g., Arnold, 2018). It is therefore possible that energy knowledge influences behaviour in the context of climate change through increasing knowledge of the probability of risks. The more people perceive climate change to be a personal risk and not as a threat that only affects future generations and developing countries, the more likely they will adapt their behaviour.

\section{DISCUSSION}

Our literature review clarifies many open questions that may inform future research into the relationship between knowledge of energy and climate literacy. First, we find that it is still necessary to further investigate the interrelations between conceptual knowledge of energy and climate change, especially with regard to energy transformation. Although the results of Visintainer et al. (2015) suggest this connection, the study was only carried out with a small sample in an age group in which conceptual knowledge of energy is still limited. However, if the link between conceptual knowledge of energy and climate change could be confirmed, intervention approaches that lead to the promotion of climate literacy could be derived on this basis. Besson and Ambrosis (2013) have already shown that by promoting specific knowledge of energy such as heat, radiation and thermal equilibrium, the understanding of climate change can be fostered. In this context, other interventions from the field of energy literacy could also be examined to assess whether they can also be applied to climate literacy. Furthermore, a similar relationship could exist between the aspect of energy transfer and knowledge of the spatial distribution pattern of climate change. This knowledge is particularly interesting in terms of addressing climate change as a socio-scientific issue, because it allows an assessment of the vulnerability of regional actors and also allows predictions regarding their motivation for taking action on a global level.

Our review has provided insufficient information to adequately address whether climate change is a suitable context for teaching the energy concept (research question 4). Climate change is certainly a phenomenon in which 
many energy-related processes take place, thus climate change should be an appropriate context to learn about the energy concept. The learning path developed by Besson and Ambrosis (2013) has not only led to a better understanding of climate change, but has also helped to build knowledge of energy, such as the concepts of heat, radiation and the thermal equilibrium state. However, this line of argumentation predominately derives from an educational, rather than a scientific discussion, because there are less complex phenomena for conveying energy aspects. The use of climate change as a context is often justified by the fact that addressing it as a socio-scientific issue creates a motivating and meaningful mediation context (e.g., Besson \& Ambrosis, 2013; Flener-Lovitt, 2014). Whether climate change is superior to other contexts in terms of increasing energy knowledge has not been adequately investigated.

Lee and Liu (2009) have for instance found that in connection with a learning progression on the energy, middle school students who have taken a physical or life science course achieve higher knowledge integration scores in terms of energy than Earth science students. In this context it is important to note, that some of the energy-related topics taught exclusively in the Earth science courses are the greenhouse effect and global warming. Most certainly the choice of the context used to teach the energy concept plays only a minor role, but it should not be neglected. Furthermore, it has also not been investigated whether the context of climate change might have a negative effect on understanding energy. Numerous studies have shown that learners have a wide range of alternative conceptions about energy-related causes of climate change (e.g., Boyes \& Stanisstreet, 1993; Choi et al., 2010; Kılınç, Stanisstreet, \& Boyes, 2008). Therefore, there is also a risk that the context of climate change could promote alternative conceptions of energy.

In connection with alternative conceptions, it could be particularly interesting to investigate specific knowledge deficits of participants in the context of energy. If respondents assume that the greenhouse effect is caused by a lower energy output, it could be because they did not understand the shift in the thermal equilibrium state. If respondents assume that the increasing temperatures during global warming are about the same across the Earth, there might be a connection with missing knowledge of energy transfer. Up to now, it has only been shown that certain alternative conceptions exist but the respective underlying reasons have not been elucidated.

Overall, an attempt should be made to investigate an energy-related learning progression on the topic of climate change. Here, most likely the thermal equilibrium state in combination with the underlying molecular energyrelated processes will determine the upper anchor. Knowledge of energy transfer processes and the development of spatial distribution patterns will likewise have an important part in an energy-related learning progression, as well as the energy transformation processes associated with the greenhouse effect.

\section{LIMITATIONS}

In this review, we attempted to clarify the relationship between one of the most important cross-cutting concepts in science (energy) and one of the most challenging environmental problems of our time (climate change). However, identifying the intersections between the energy concept and climate literacy has been a major challenge. There are thousands of entries in the research databases for both thematic areas. The identification of all relevant articles can only be achieved approximately. Furthermore, we concentrated our review on the interrelations between energy knowledge and knowledge of climate change as well as climate change related behaviours. From a science education perspective these are some of the most important overlaps.

Another major challenge is that the existing assessment instruments for climate change knowledge primarily take declarative knowledge into account and do not focus on climate literacy or on conceptual knowledge of climate change. Many results from studies are therefore difficult to compare, because they were not conducted using comparable measures (e.g. Bedford, 2015; Guy et al., 2014; Kahan et al., 2012). In this review, we therefore conducted independent analysis of the relationship between the knowledge dimensions and climate change related behaviour, although both aspects can be subsumed under the definition of climate literacy.

Furthermore, learners across all disciplines tend only to have a partially-developed knowledge of energy (e.g., Herrmann-Abell, \& DeBoer, 2018; Opitz, Harms, Neumann, \& Bernholt, 2017). Therefore, the problem arises that studies focusing on the connection between energy knowledge and climate literacy must first of all find participants with adequate energy knowledge or carry out an intervention which fosters it. This challenge in connection with the absence of comparable climate literacy test instruments could be one reason why, so far, few studies have examined the connection between energy knowledge and climate literacy.

A final challenge is that many studies are mainly published in North America. Although there are many studies that are also published in Europe and Asia, the majority is from English-speaking areas. In addition, a large proportion of articles only described the participants instead of justifying their choice. In the field of climate change, however, we know that regional and cultural backgrounds have a significant influence on the perception of climate change (e.g., Lee et al., 2015). Accordingly, the selection of test persons should have been taken more into account 
and many results should have been reflected more strongly with regard to their generalisability. Therefore, there are also uncertainties in the generalisability of our results to different regions.

Despite these limitations, our review contributes to the existing literature base by revealing the close relationship between the energy concept and climate literacy. Furthermore it aids the scientific community in reaching its long-term educational goal to enable citizens not only to understand climate change but also make informed decisions in this respect.

\section{ACKNOWLEDGEMENTS}

The authors are grateful to Dr. Sebastian Opitz for comments and discussions during the process of writing the review.

\section{REFERENCES}

Aksit, O., McNeal, K. S., Gold, A. U., Libarkin, J. C., \& Harris, S. (2018). The influence of instruction, prior knowledge, and values on climate change risk perception among undergraduates. Journal of Research in Science Teaching, 55(4), 550-572. https:/ / doi.org/10.1002/ tea.21430

Aksüt, P., Doğan, N., \& Bahar, M. (2016). If you change yourself, the world changes: the effect of exhibition on preservice science teachers' views about global climate change. Eurasia Journal of Mathematics, Science $\mathcal{E}$ Technology Education, 12(12). https:/ / doi.org/10.12973/eurasia.2016.02314a

Allum, N., Sturgis, P., Tabourazi, D., \& Brunton-Smith, I. (2008). Science knowledge and attitudes across cultures: A meta-analysis. Public Understanding of Science, 17(1), 35-54. https:/ / doi.org/10.1177/0963662506070159

Alonzo, A. C., \& Gotwals, A. W. (Eds.). (2012). Learning progressions in science: Current challenges and future directions. Springer Science \& Business Media.

Ambusaidi, A., Boyes, E., Stanisstreet, M., \& Taylor, N. (2012a). Omani Pre-Service Science Teachers' Views about Global Warming: Beliefs about Actions and Willingness to Act. International Journal of Environmental and Science Education, 7(2), 233-251.

Ambusaidi, A., Boyes, E., Stanisstreet, M., \& Taylor, N. (2012b). Omani Students' Views about Global Warming: Beliefs about Actions and Willingness to Act. International Research in Geographical and Environmental Education, 21(1), 21-39. https:/ / doi.org/10.1080/10382046.2012.639154

Arnold, J. C. (2018). An integrated model of decision-making in health contexts: the role of science education in health education. International Journal of Science Education, 40(5), 519-537. https:/ / doi.org/10.1080/09500693.2018.1434721

Avramides, K., Craft, B., and Luckin, R. (2013). Modelling teenage personal contexts to support technology enhanced enquiry into personal energy consumption. Computers and Education, 69, 377-386. https:/ / doi.org/10.1016/j.compedu.2013.07.019

Avramides, K., Craft, B., and Luckin, R. (2016). Understanding teenagers' personal contexts to design technology that supports learning about energy consumption. Interactive Learning Environments, 24(1), 33-48. https:/ / doi.org/10.1080/10494820.2013.817438

Bedford, D. (2015). Does Climate Literacy Matter? A Case Study of US Students' Level of Concern about Anthropogenic Global Warming. Journal of Geography, 1-11. https:/ / doi.org/10.1080/00221341.2015.1105851

Besson, U., \& Ambrosis, A. de. (2013). Teaching Energy Concepts by Working on Themes of Cultural and Environmental Value. Science and Education, 23(6), 1309-1338. https:/ / doi.org/10.1007/s11191-013-9592-7

Boyes, E., and Stanisstreet, M. (1993). The 'Greenhouse Effect ': children's perceptions of causes, consequences and cures. International Journal of Science Education, 15(5), 531-552. https:/ / doi.org/10.1080/0950069930150507

Boyes, E., Skamp, K., and Stanisstreet, M. (2009). Australian Secondary Students' Views about Global Warming: Beliefs about Actions, and Willingness to Act. Research in Science Education, 39(5), 661-680. https:/ / doi.org/10.1007/s11165-008-9098-5

Breslyn, W., Drewes, A., McGinnis, J. R., Hestness, E., \& Mouza, C. (2017). Development of an Empirically-Based Conditional Learning Progression for Climate Change. Science Education International, 28(3), 214-223.

Breslyn, W., McGinnis, J. R., McDonald, R. C., \& Hestness, E. (2016). Developing a learning progression for sea level rise, a major impact of climate change. Journal of Research in Science Teaching, 53(10), 1471-1499. https://doi.org/10.1002/tea.21333 
Chao, Y.-L., Chou, Y.-C., Yen, H.-Y., \& Chen, S.-J. (2017). The Effects of Earth Science Textbook Contents on High School Students' Knowledge of, Attitude toward, and Behavior of Energy Saving and Carbon Reduction. Science Education International, 28(1), 30-52.

Chen, J., \& Anderson, C. W. (2015). Comparing American and Chinese Students' Learning Progression on Carbon Cycling in Socio-Ecological Systems. Science Education International, 26(4), 439-462.

Choi, S., Niyogi, D., Shepardson, D. P., \& Charusombat, U. (2010). Do Earth and Environmental Science Textbooks Promote Middle and High School Students' Conceptual Development about Climate Change? Textbooks' consideration of students' misconceptions. Bulletin of the American Meteorological Society, 91(7), 889-898. https:/ / doi.org/10.1175/2009BAMS2625.1

Christensen, R., \& Knezek, G. (2018). Impact of Middle School Student Energy Monitoring Activities on Climate Change Beliefs and Intentions. School Science and Mathematics, 118(1-2), 43-52. https:/ / doi.org/10.1111/ssm.12257

Dietz, T., Dan, A., \& Shwom, R. (2007). Support for Climate Change Policy: Social Psychological and Social Structural Influences. Rural Sociology, 72(2), 185-214. https:/ / doi.org/10.1526/003601107781170026

Duit, R. (1984). Learning the energy concept in school-empirical results from the Philippines and West Germany. Physics Education, 19, 59.

Duit, R. (1991). Students' conceptual frameworks: Consequences for learning science. The psychology of learning science, 75(6), 649-72.

Duit, R. (2014). Teaching and Learning the Physics Energy Concept. In R. F. Chen, A. Eisenkraft, D. Fortus, J. Krajcik, K. Neumann, J. Nordine, and A. Scheff (Eds.), Teaching and Learning of Energy in K - 12 Education. Cham: Springer International Publishing. https:/ / doi.org/10.1007/978-3-319-05017-1_5

Flener-Lovitt, C. (2014). Using the Socioscientific Context of Climate Change to Teach Chemical Content and the Nature of Science. Journal of Chemical Education, 91(10), 1587-1593. https:/ / doi.org/10.1021/ed4006985

Frappart, S., Moine, M., Jmel, S., \& Megalakaki, O. (2018). Exploring French adolescents' and adults' comprehension of the greenhouse effect. Environmental Education Research, 24(3), 378-405. https:/ / doi.org/10.1080/13504622.2016.1147529

Giorgetta, M. A., Jungclaus, J., Reick, C. H., Legutke, S., Bader, J., Böttinger, M., . . Stevens, B. (2013). Climate and carbon cycle changes from 1850 to 2100 in MPI-ESM simulations for the Coupled Model Intercomparison Project phase 5. Journal of Advances in Modeling Earth Systems, 5(3), 572-597. https://doi.org/10.1002/jame.20038

Guy, S., Kashima, Y., Walker, I., \& O'Neill, S. (2014). Investigating the effects of knowledge and ideology on climate change beliefs. European Journal of Social Psychology, 44(5), 421-429. https:/ / doi.org/10.1002/ ejsp.2039

Hansen, P. J. K. (2010). Knowledge about the Greenhouse Effect and the Effects of the Ozone Layer among Norwegian Pupils Finishing Compulsory Education in 1989, 1993, and 2005 -What Now? International Journal of Science Education, 32(3), 397-419. https:/ / doi.org/10.1080/09500690802600787

Harlen, W. (2015). Working with Big Ideas of Science Education. Trieste: Science Education Programme of IAP.

Herrmann-Abell, C. F., \& DeBoer, G. E. (2018). Investigating a learning progression for energy ideas from upper elementary through high school. Journal of Research in Science Teaching, 55(1), 68-93. https://doi.org/10.1002/tea.21411

Higgins, J., \& Green, S. (2011). Cochrane Handbook for Systematic Reviews of Interventions Version 5.1.0. Retrieved from http://handbook-5-1.cochrane.org/

Hokayem, H., \& Gotwals, A. W. (2016). Early elementary students' understanding of complex ecosystems: A learning progression approach. Journal of Research in Science Teaching, 53(10), 1524-1545. https://doi.org/10.1002/tea.21336

Jho, H., Yoon, H. G., \& Kim, M. (2014). The relationship of science knowledge, attitude and decision making on socio-scientific issues: The case study of students' debates on a nuclear power plant in Korea. Science $\mathcal{E}$ Education, 23(5), 1131-1151. https:/ / doi.org/10.1007/s11191-013-9652-z

Jin, H., \& Anderson, C. W. (2012). A Learning Progression for Energy in Socio-Ecological Systems. Journal of Research in Science Teaching, 49(9), 1149-1180. https:/ / doi.org/10.1002/tea.21051

Jin, H., Zhan, L., \& Anderson, C. W. (2013). Developing a fine-grained learning progression framework for carbontransforming processes. International Journal of Science Education, 35(10), 1663-1697. https://doi.org/10.1080/09500693.2013.782453 
Kahan, D. M., Peters, E., Wittlin, M., Slovic, P., Ouellette, L. L., Braman, D., \& Mandel, G. (2012). The polarizing impact of science literacy and numeracy on perceived climate change risks. Nature Climate Change, 2(10), 732-735. https:/ / doi.org/10.1038/nclimate1547

Kılınç, A., Boyes, E., \& Stanisstreet, M. (2010). Turkish School Students and Global Warming: Beliefs and Willingness to Act. Eurasia Journal of Mathematics Science and Technology Education, 7(2), 121-134.

Kılınç, A., Boyes, E., \& Stanisstreet, M. (2013). Exploring Students' Ideas about Risks and Benefits of Nuclear Power Using Risk Perception Theories. Journal of Science Education and Technology, 22(3), 252-266. https:/ / doi.org/10.1007/s10956-012-9390-z

Kılınç, A., Stanisstreet, M., \& Boyes, E. (2008). Turkish Students' Ideas about Global Warming. International Journal of Environmental and Science Education, 3(2), 89-98.

Krathwohl, D. R. (2002). A Revision of Bloom's Taxonomy: An Overview. Theory into Practice, 41(4), 212-218.

Law, M., Stewart, D., Letts, L., Pollock, N., Bosch, J., \& Westmorland, M. (1998). Guidelines for critical review of qualitative studies. McMaster University Occupational Therapy Evidence-Based Practice Research Group.

Lee, H. S., \& Liu, O. L. (2010). Assessing learning progression of energy concepts across middle school grades: The knowledge integration perspective. Science Education, 94(4), 665-688. https:/ / doi.org/10.1002/ sce.20382

Lee, T. M., Markowitz, E. M., Howe, P. D., Ko, C.-Y., \& Leiserowitz, A. A. (2015). Predictors of public climate change awareness and risk perception around the world. Nature Climate Change, 5(11), 1014-1020. https://doi.org/10.1038/nclimate2728

Leiserowitz, A., Maibach, E., Roser-Renouf, C., Feinberg, G., \& Rosenthal, S. (2015). Climate change in the American mind. Yale University and George Mason University. New Haven, CT: Yale Program on Climate Change Communication. Retrieved from http://climatecommunication.yale.edu/wpcontent/uploads/2015/11/Climate-Change-American-Mind-October-20151.pdf

Leiserowitz, A., Smith, N., \& Marlon, J. R. (2010). Americans' Knowledge of Climate Change. Yale University and George Mason University. New Haven, CT: Yale Program on Climate Change Communication. Retrieved from http:/ / environment.yale.edu/climate/files/Climate ChangeKnowledge2010.pdf

Linn, M. C., Bell, P., \& Davis, E. A. (2004). Specific design principles: Elaborating the scaffolded knowledge integration framework. Internet environments for science education, 315-340.

Liu, W., Xie, S.-P., Liu, Z., \& Zhu, J. (2017). Overlooked possibility of a collapsed Atlantic Meridional Overturning Circulation in warming climate. Science Advances, 3(1), e1601666. https:/ / doi.org/10.1126/sciadv.1601666

Martens, T., \& Rost, J. (1998). The relationship between the perceived threat of environmental problems and the formation of action intentions. Experimental Psychology, 45(4), 345-364.

Mazze, S., \& Stockard, J. (2013). Evaluating the Effectiveness of a Sustainable Living Education Program. Journal of Extension, 51(1).

McGinnis, J. R., McDonald, C., Breslyn, W., \& Hestness, E. (2017). Supporting the inclusion of climate change in US science education curricula by use of learning progressions. Teaching and learning about climate change: A framework for educators, 135-151.

Mohan, L., Chen, J., and Anderson, C. W. (2009). Developing a multi-year learning progression for carbon cycling in socio-ecological systems. Journal of Research in Science Teaching, 46(6), 675-698. https://doi.org/10.1002/tea.20314

Moher, D., Liberati, A., Tetzlaff, J., Altman, D. G., Group, P., et al. (2009). Preferred reporting items for systematic reviews and meta-analyses: The PRISMA statement. PLoS Medicine, 6(7), e1000097.

Moss, R. H., Edmonds, J. A., Hibbard, K. A., Manning, M. R., Rose, S. K., van Vuuren, D. P., . . Wilbanks, T. J. (2010). The next generation of scenarios for climate change research and assessment. Nature, 463(7282), 747756. https:/ / doi.org/10.1038/nature08823

National Research Council (NRC). (2012). A Framework for K-12 Science Education: Practices, crosscutting concepts, and core ideas. Washington, D.C.: National Academies Press.

Neumann, K., Viering, T., Boone, W. J., \& Fischer, H. E. (2013). Towards a learning progression of energy. Journal of research in science teaching, 50(2), 162-188. https:/ / doi.org/10.1002/ tea.21061

Niebert, K., \& Gropengießer, H. (2014). Understanding the greenhouse effect by embodiment-analysing and using students' and scientists' conceptual resources. International Journal of Science Education, 36(2), 277-303. https:/ / doi.org/10.1080/09500693.2013.763298

Opitz, S., Harms, U., Neumann, K., Kowalzik, K., \& Frank, A. (2015). Students' energy concepts at the transition between primary and secondary school. Research in Science Education, 49(5), 691-715. https:// doi.org/10.1007/s11165-014-9444-8 
Pachauri, R. K., Allen, M. R., Barros, V. R., Broome, J., Cramer, W., Christ, R., .. Dubash, N. K. (2014). Climate change 2014: synthesis report. Contribution of Working Groups I, II and III to the fifth assessment report of the Intergovernmental Panel on Climate Change (p. 151). IPCC.

Parker, J. M., de los Santos, Elizabeth X., \& Anderson, C. W. (2013). What learning progressions on carbontransforming processes tell us about how students learn to use the laws of conservation of matter and energy. Educación Química, 24(4), 399-406. https:/ / doi.org/10.1016/S0187-893X(13)72493-5

Parker, J. M., de los Santos, Elizabeth X., \& Anderson, C. W. (2015). Learning progressions \& climate change. The American Biology Teacher, 77(4), 232-238. https://doi.org/10.1525/abt.2015.77.4.2

Sadler, T. D., Klosterman, M. L., \& Topcu, M. S. (2011). Learning science content and socio-scientific reasoning through classroom explorations of global climate change. In Socio-scientific Issues in the Classroom (pp. 45-77). Springer, Dordrecht.

Sakschewski, M., Eggert, S., Schneider, S., \& Bögeholz, S. (2014). Students' Socioscientific Reasoning and Decisionmaking on Energy-related Issues: Development of a measurement instrument. International Journal of Science Education, 36(14), 2291-2313. https:/ / doi.org/10.1080/09500693.2014.920550

Schramm, J. W., Jin, H., Keeling, E. G., Johnson, M., \& Shin, H. J. (2018). Improved Student Reasoning About Carbon-Transforming Processes Through Inquiry-Based Learning Activities Derived from an Empirically Validated Learning Progression. Research in Science Education, 48(5), 887-911. https:/ / doi.org/10.1007/s11165-016-9584-0

Shepardson, D. P., Niyogi, D., Choi, S., \& Charusombat, U. (2009). Seventh grade students' conceptions of global warming and climate change. Environmental Education Research, 15(5), 549-570. https:/ / doi.org/10.1080/13504620903114592

Svihla, V., \& Linn, M. C. (2012). A design-based approach to fostering understanding of global climate change. International Journal of Science Education, 34(5), 651-676. https:/ / doi.org/10.1080/09500693.2011.597453

U.S. Global Change Research Program. (2009). Climate literacy: The essential principles of climate. Retrieved from https:/ / downloads.globalchange.gov/Literacy/climate_literacy_lowres_english.pdf

Visintainer, T., \& Linn, M. (2015). Sixth-Grade Students' Progress in Understanding the Mechanisms of Global Climate Change. Journal of Science Education and Technology, 24(2-3), 287-310. https:/ / doi.org/10.1007/s10956-014-9538-0

You, H. S., Marshall, J. A., \& Delgado, C. (2018). Assessing students' disciplinary and interdisciplinary understanding of global carbon cycling. J. Res. Sci. Teach. 55(3), 377-398. https:// doi.org/10.1002/tea.21423

Zangori, L., Peel, A., Kinslow, A., Friedrichsen, P., \& Sadler, T. D. (2017). Student development of model-based reasoning about carbon cycling and climate change in a socio-scientific issues unit. Journal of Research in Science Teaching, 54(10), 1249-1273. https:/ / doi.org/10.1002/tea.21404

Zeidler, D. L., Sadler, T. D., Simmons, M. L., \& Howes, E. V. (2005). Beyond STS: A research-based framework for socioscientific issues education. Science education, 89(3), 357-377.

\section{http://www.ejmste.com}

